\title{
Studi Kepiting Mangrove di Delta Mahakam, Kalimantan Timur
}

\author{
A Study of Mangrove Crabs at Mahakam Delta, East Kalimantan \\ Rianta Pratiwi \\ Bidang Sumberdaya Laut, Pusat Penelitian Oseanografi-LIPI Jl. Pasir Putih 1. Ancol Timur, Jakarta 14430 \\ Tel.: 62.21.6471.38.50; Fax: 62.21.6471.19.48; E-mail:r_pratiwi_99@yahoo.com
}

\begin{abstract}
The research was carried out in July 2004 at Makaham Delta, East Kalimantan. This research observed the diversity and the distribution pattern of mangrove crabs at muara Ilu, Kaely, Bayor, and Beji. There are 33 species consisting of 7 families and 6908 individu of crabs found in this research. Most of the mangroves crabs are clump distributed. The research method by using frame transects $1 \mathrm{~m}^{2} \times 1 \mathrm{~m}^{2}$ with 5 up to 10 meters distance (based on the thickness of mangrove in those areas). The distribution pattern of crabs analyze by using Index Morisita according to Brower and Zar.
\end{abstract}

Key words: mangrove crabs, diversity, distribution pattern, Mahakam Delta, East Kalimantan

Diterima: 05 Agustus 2006, disetujui: 06 Maret 2007

\section{Pendahuluan}

Sebagai ekosistem yang spesifik, mangrove memiliki keterkaitan di dalam proses kehidupan biota (flora dan fauna) yang terdapat di lingkungan daratan maupun di lingkungan laut. Oleh karenanya, ekosistem mangrove sering disebut sebagai suatu ekosistem peralihan yang berperan penting dalam mendukung keseimbangan ekosistem perairan maupun ekosistem daratan di sekitarnya (Purnobasuki, 2004).

Dilihat dari segi ekosistem perairan, hutan mangrove mempunyai arti yang penting. Berbagai jenis hewan laut hidup di kawasan ini atau bergantung pada keberadaan hutan mangrove. Ekosistem mangrove berfungsi antara lain sebagai tempat pemijahan (spawning ground), tempat pembesaran (nursery ground) dan mencari makan (feeding ground) bagi berbagai jenis hewan seperti: ikan, udang, dan kepiting. Sebagai daerah peralihan terestrial dan marin, maka mangrove memiliki ciri khas fauna yang hidup di lingkungan tersebut (Nybakken, 1992; Rahawarin, 2005). Avertebrata yang hidup di hutan mangrove terdiri dari berbagai filum di antaranya Krustasea dan moluska. Kedua filum tersebut merupakan avertebrata yang keberadaannya paling mencolok dan tertinggi kelimpahannya (Hogarth, 1999). Daerah mangrove kaya akan nutrien dan memiliki temperatur, cahaya, $\mathrm{pH}$, oksigen, dan salinitas yang cukup optimum, serta kondisi perairan yang tenang, merupakan habitat yang sesuai bagi Krustasea (Bliss, 1983)

Wilayah pesisir Delta Mahakam, Kalimantan Timur merupakan kawasan pesisir yang memiliki sumberdaya alam yang sangat potensial. Terkait dengan hal tersebut, maka aktivitas manusia semakin tinggi, seperti misalnya bertambahnya pembangunan di kawasan tersebut dapat memberikan dampak yang mengkhawatirkan terhadap keseimbangan ekosistem di Delta Mahakam. Menurut Pramudji (2004) perubahan lingkungan yang paling utama berasal dari kegiatan manusia contohnya konversi lahan mangrove menjadi areal pertambakan, pemukiman, pertanian, dan pariwisata. Hal ini terjadi pada ekosistem mangrove di Delta Mahakam, Kalimantan Timur. Kerusakan yang terjadi di daerah ini 
adalah konversi lahan untuk pertambakan dan penebangan hutan yang tidak mengikuti aturan menyebabkan penurunan kualitas habitat mangrove dan tidak berfungsinya mangrove sebagai tempat mencari makan, tempat pemijahan dan tempat asuhan larva beberapa jenis organisme. Menurut Werdiningsih (2005), kerusakan habitat mangrove dapat mengancam regenerasi sumberdaya fauna perairan pesisir terutama kepiting. Hal tersebut menghambat aliran energi, dan siklus nutrien yang dilakukan oleh kepiting.

Penelitian struktur komunitas Krustasea mangrove dilakukan di Delta Mahakam, Kalimantan Timur mulai dari lantai hutan mangrove hingga perairan sekitar muara. Adapun tujuan dari penelitian ini adalah: 1) untuk mengetahui struktur komunitas hewan Krustasea di sekitar Delta Mahakam serta beberapa aspek biologi sebagai acuan bagi penelitian selanjutnya. 2) untuk memperoleh gambaran berbagai aspek yang berpengaruh terhadap menurunnya kondisi ekosistem mangrove terutama kaitannya dengan biota asosiasi termasuk hewan Krustasea salah satunya.

\section{Metode Penelitian}

Penelitian dilakukan pada bulan Juli 2004 di Delta Mahakam yang meliputi: Muara Ilu, Muara Kaeli, Muara Bayor dan Muara Beji (Gambar 1). Setiap lokasi (stasiun) 4 plot (disesuaikan dengan kondisi muara). Plot menggunakan frame berukuran $1 \mathrm{~m}^{2}$ dengan jarak setiap plot adalah 5 - 10 meter (tergantung dari ketebalan mangrove di daerah tersebut).

Pengambilan sampel Krustasea dalam komunitas mangrove dilakukan secara kuantitatif pada saat sampling tidak memperhitungkan volume atau kedalaman substrat. Pada tiap-tiap sampling kuadrat $(1 \mathrm{x}$ $1 \mathrm{~m})$, Krustasea yang ada dipermukaan substrat diambil dengan tangan (hand picking). Krustasea yang terdapat di dalam lubang diambil dengan cara menggali lubang dan menggunakan sekop. Metoda pengambilan sampel ini diadaptasi dari cara yang digunakan oleh Sasekumar (1974) dan Frith et al., (1976).

Pengambilan sampel dilakukan saat air surut.

Identifikasi sampel menggunakan bukubuku panduan identifikasi Krustasea: Banner \& Banner (1966, 1982); Crane (1975); Fize \& Serene (1955); Holthuis (1955); Moosa \& Juwana (1996) dan Sakai (1976 a dan b). Untuk mengetahui pola sebaran jenis kepiting digunakan indeks penyebaran Morisita (Brower \& Zar, 1977) dengan rumus sebagai berikut:

$$
1 \delta=\mathrm{n} \frac{\sum \mathrm{x}^{2}-\mathrm{N}}{\Sigma \mathrm{N}(\mathrm{N}-1)}
$$

Keterangan:

$1 \delta=$ Indeks penyebaran Morisita

$\mathrm{n} \quad=$ Jumlah petak pengambilan contoh

$\mathrm{N}$ = Jumlah individu yang diperoleh pada seluruh petak contoh

$\Sigma \mathrm{x}^{2}=$ Jumlah total dari kuadrat individu tiap petak contoh

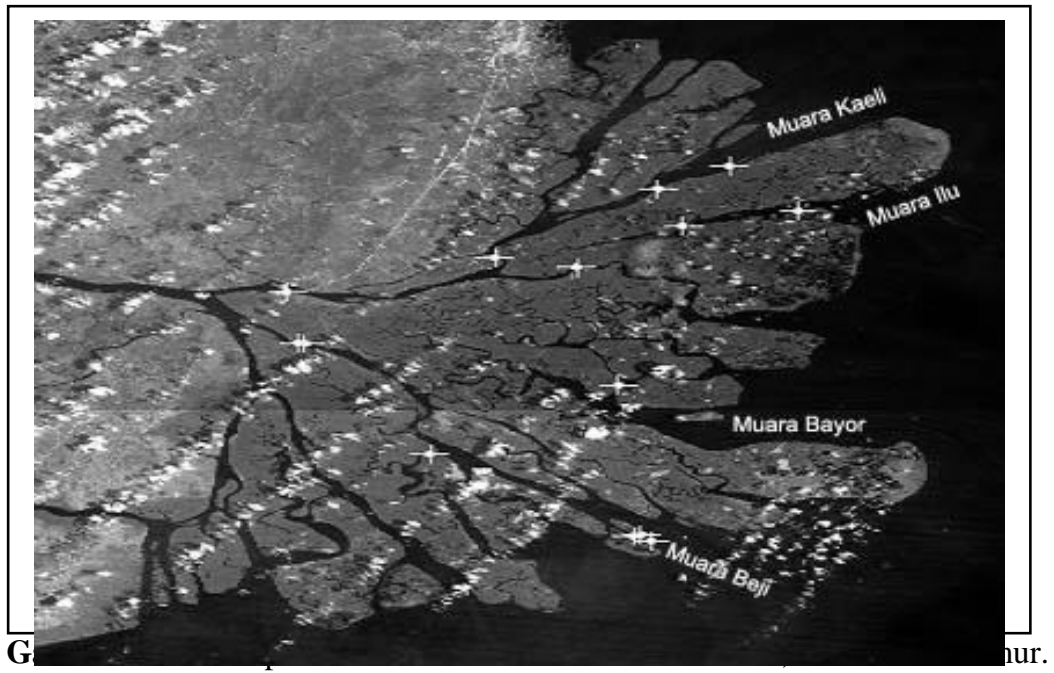




\section{Hasil dan Pembahasan}

\section{Komposisi jenis kepiting di lokasi penelitian}

Berdasarkan hasil penelitian secara keseluruhan di lokasi Muara Ilu, Kaeli, Bayor, dan Beji ditemukan sebanyak 6.908 individu, 33 jenis, dan 7 famili. Untuk Di Muara Ilu ditemukan hanya 2 famili, 8 jenis, 168 individu. Muara Kaeli ditemukan 3 famili, 16 jenis, 2845 individu. Muara Bayor ditemukan 7 famili, 23 jenis, 3279 individu dan Muara Beji ditemukan 4 famili, 12 jenis serta 616 jumlah individu (Tabel 1).

Pada Tabel 1 dan Gambar 2 - 3 terlihat bahwa terdapat cukup banyak jenis yang jumlah individunya sangat banyak ditemukan di muara Kaeli dan Bayor tetapi tidak ditemukan atau sedikit jumlahnya di muara Ilu dan Beji, begitu pula sebaliknya. Hal ini disebabkan mangrove di muara Bayor memiliki kondisi paling baik. Vegetasi mangrove di muara Bayor masih baik dalam arti belum diaganggu oleh ulah manusia, masih lebat dan memiliki keanekaragaman yang tinggi diantara mangrove yang ada di Delta Mahakam. Selain itu disebabkan juga daerah tersebut memiliki jumlah vegetasi dan tegakan cukup banyak, sehingga jenis kepiting dari suku Sesarmidae dan Ocypodidae yang merupakan pemakan daun mangrove sangat banyak ditemukan dan kedua kepiting dari suku tersebut merupakan jenis yang paling dominan. Keadaan yang serupa dinyatakan oleh Macinthos et al., (2002) dalam penelitiannya di mangrove Klong Ngao, Thailand ditemukan jenis kepiting yang paling dominan adalah dari suku Sesarmidae dan Ocypodidae. Kondisi mangrove di daerah penelitian sangat lebat dan merupakan jalur hijau, artinya belum ada kerusakan oleh manusia.

Ketebalan mangrove di muara Bayor lebih kurang 300 meter dan memiliki keanekaragaman tinggi serta kondisi lingkungan yang cukup baik dengan substrat lumpur liat. Kondisi mangrove di muara Kaeli relatif cukup baik meskipun di bagian tepi sungai telah terjadi abrasi yang tinggi akibat arus yang kuat. Substrat di daerah tersebut adalah lumpur. Komposisi dari suku Sesarmidae dan Ocypodidae tidak jauh berbeda dengan di muara Bayor.

Kedua muara lainnya yaitu Muara Ilu dan Beji, ditumbuhi oleh mangrove yang tidak terlalu lebat dan kondisi lingkungannyapun sudah banyak mengalami tekanan dengan adanya pertambakkan dan pemukiman. Diduga hal tersebut sangat berpengaruh terhadap keberadaan kepiting, sehingga jumlah jenis dan jumlah individu tidak terlalu banyak. Macinthos et al., (2002) mengamati kepiting suku Ocypodidae biasanya ditemukan di area terbuka dan semi terbuka dengan cukup penetrasi cahaya matahari langsung. Hal tersebut sangat berbeda dengan kondisi di muara Ilu dan Beji, untuk suku Ocypodidae (jenis kepiting $U c a$ spp) jumlah dan individunya tidak terlalu banyak dijumpai meskipun terdapat di area terbuka. Kondisi tersebut diduga karena area tersebut sudah banyak mengalami kerusakan dengan adanya pertambakan dan pemukiman. Gambar 4, menunjukkan densitas individu kepiting/ $\mathrm{m}^{2}$ yang ditemukan pada tiap-tiap stasiun terlihat sangat mencolok perbandingannya antara Muara Bayor dan Kaeli dengan Muara Beji dan Ilu. Jumlah individu terbesar ditemukan di Muara Bayor terdapat di stasiun 3 dan Muara Kaeli di stasiun 2. Jumlah individu terkecil ditemukan di Muara Ilu stasiun 1 dan Muara Beji stasiun 4.

Secara keseluruhan keanekaragaman dan kelimpahan kepiting di Muara Bayor dan Kaeli berbeda dengan Muara Beji dan Ilu, terutama untuk kelimpahan beberapa jenis tertentu Suku Grapsidae dan Ocypodidae. Keadaan tersebut sesuai dengan pendapat Odum (1971) yang menyatakan bahwa dalam suatu komunitas yang mengandung banyak jenis, beberapa diantaranya merupakan kelompok predominan. Jumlah jenis yang termasuk predominan berkurang jika suatu lingkungan menjadi ekstrim yaitu mengalami gangguan tekanan lingkungan baik secara fisik, biologi, dan kimia (Pratiwi, 2002). 
Rianta Pratiwi

Tabel 1. Jenis dan cacah individu kepiting mangrove di muara Ilu, Kaely, Bayor dan Beji

\begin{tabular}{|c|c|c|c|c|c|}
\hline \multirow[t]{2}{*}{ Suku } & \multirow{2}{*}{ Jenis } & \multicolumn{4}{|c|}{ Jumlah individu } \\
\hline & & Ilu & Kaely & Bayor & Beji \\
\hline Coenobitidae & Coenobita sp. & $\overline{-1}$ & 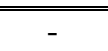 & 1 & \\
\hline \multirow[t]{2}{*}{ Diogenidae } & Clibanarius infraspinatus & - & - & 1 & - \\
\hline & Diogenes sp. & - & - & 3 & - \\
\hline \multirow[t]{17}{*}{ Sesarmidae } & Clistoceoloma sp. & - & & 2 & - \\
\hline & Episesarma lafondi & - & - & - & 1 \\
\hline & Metopograpsus messor & 1 & 8 & - & - \\
\hline & Metaplax sp. Nov & - & - & 7 & 1 \\
\hline & Parasesarma bidens & 1 & - & - & - \\
\hline & Parasesarma bidens var indiarum & - & 7 & - & - \\
\hline & Parasesarma crassa & - & - & - & 4 \\
\hline & Parasesarma crassimanus & 26 & 60 & 93 & - \\
\hline & Parasesarma eumolpe & - & 21 & - & - \\
\hline & Parasesarma gemmifera & 28 & - & - & - \\
\hline & Parasesarma pictum & - & 53 & 49 & - \\
\hline & Parasesarma plicatum & - & 38 & 47 & 45 \\
\hline & Parasesarma sp. & - & 283 & - & - \\
\hline & Perisesarma dussumieri & 38 & 545 & 966 & 156 \\
\hline & Sarmatium crassum & 61 & 973 & 862 & 85 \\
\hline & Sarmatium sp. & - & 3 & - & - \\
\hline & Varuna yui & - & 123 & - & 226 \\
\hline \multirow[t]{7}{*}{ Ocypodidae } & Macrophthalmus convexus & - & - & 33 & - \\
\hline & Uca annulipes & - & - & 48 & 2 \\
\hline & Uca arcuata & - & 55 & 12 & - \\
\hline & Uca bellator minima & - & 44 & 11 & - \\
\hline & Uca coarctata & 8 & 229 & 28 & 27 \\
\hline & Uca dussumieri & 5 & 392 & 912 & 65 \\
\hline & Uca flammula & - & - & 81 & - \\
\hline Paguridae & Pagurus sp. & - & - & 6 & 1 \\
\hline \multirow[t]{4}{*}{ Portunidae } & Charybdis demani & - & - & 24 & - \\
\hline & Charybdis feriatus & - & - & 17 & 3 \\
\hline & Charybdis variegate & - & - & 44 & - \\
\hline & Scylla serrata & - & 11 & 31 & - \\
\hline \multirow[t]{2}{*}{ Squillidae } & Oratosquilla perpensa & - & - & 1 & - \\
\hline & $\begin{array}{l}\text { Jumlah Jenis } \\
\text { Jumlah Individu }\end{array}$ & $\begin{array}{c}8 \\
168\end{array}$ & $\begin{array}{c}16 \\
2845\end{array}$ & $\begin{array}{c}23 \\
3279\end{array}$ & $\begin{array}{l}12 \\
616\end{array}$ \\
\hline
\end{tabular}

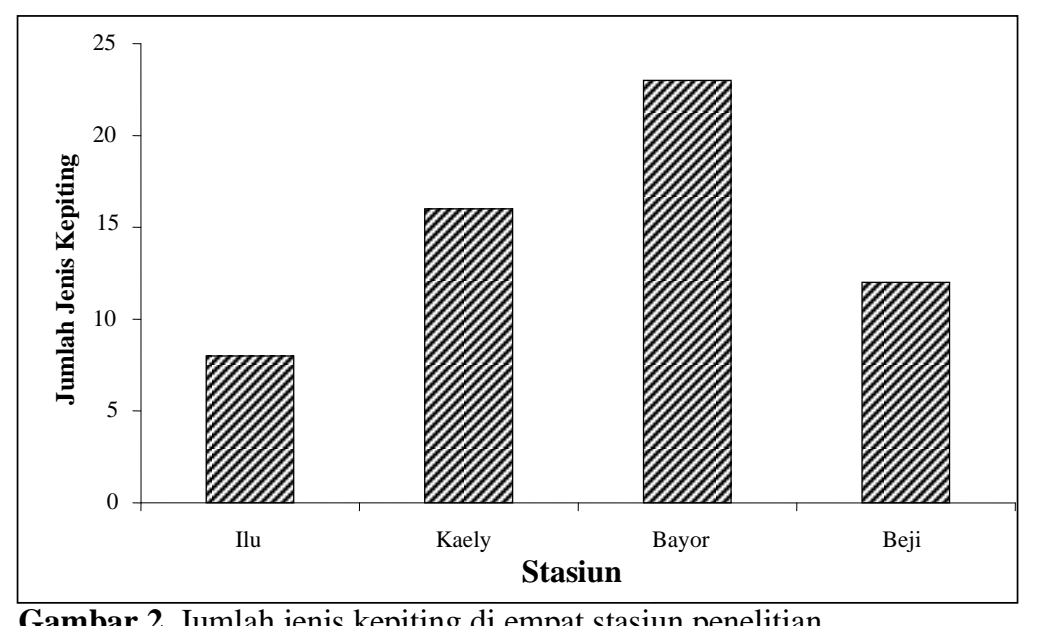

Gambar 2. Jumlah jenis kepiting di empat stasiun penelitian 


\section{Pola sebaran kepiting}

Pola penyebaran organisme pada suatu lingkungan perairan dipengaruhi oleh parameter fisika dan kimia di habitat organisme tersebut.

Sebaran jenis organisme dibedakan atas: Pola sebaran individu seragam $1 \delta<1$. Pola sebaran individu acak $1 \delta=1$. Pola sebaran individu mengelompok $1 \delta>1$. Hasil dari nilai indeks penyebaran Morisita, pola penyebaran kepiting di Muara Ilu, Kaely, Bayor dan Beji, Kalimantan Timur sebagian besar adalah mengelompok (Tabel 2).

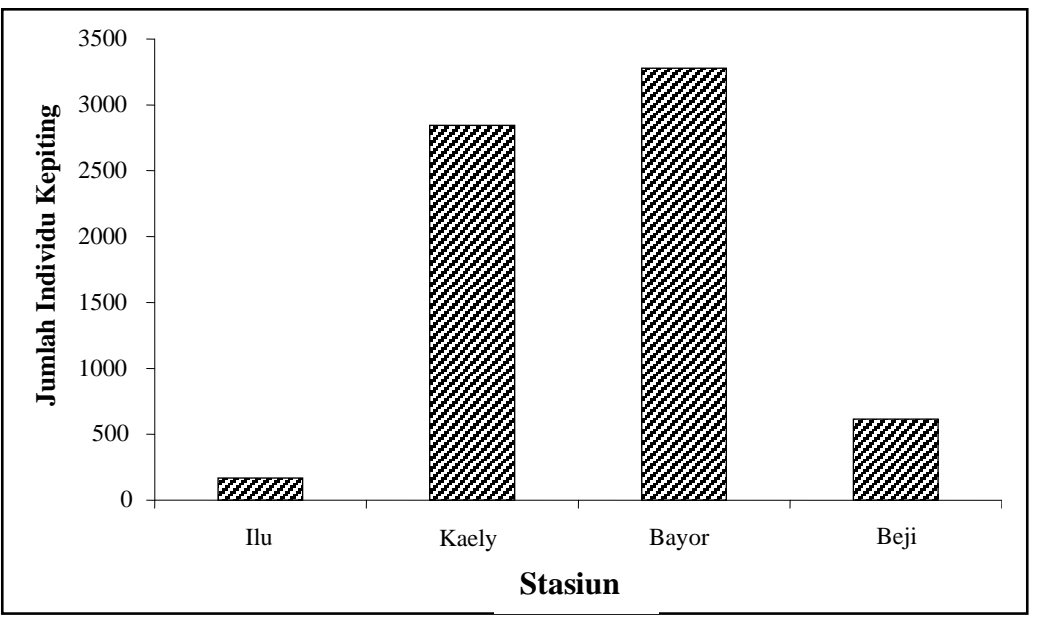

Gambar 3. Jumlah individu kepiting di empat stasiun penelitian.

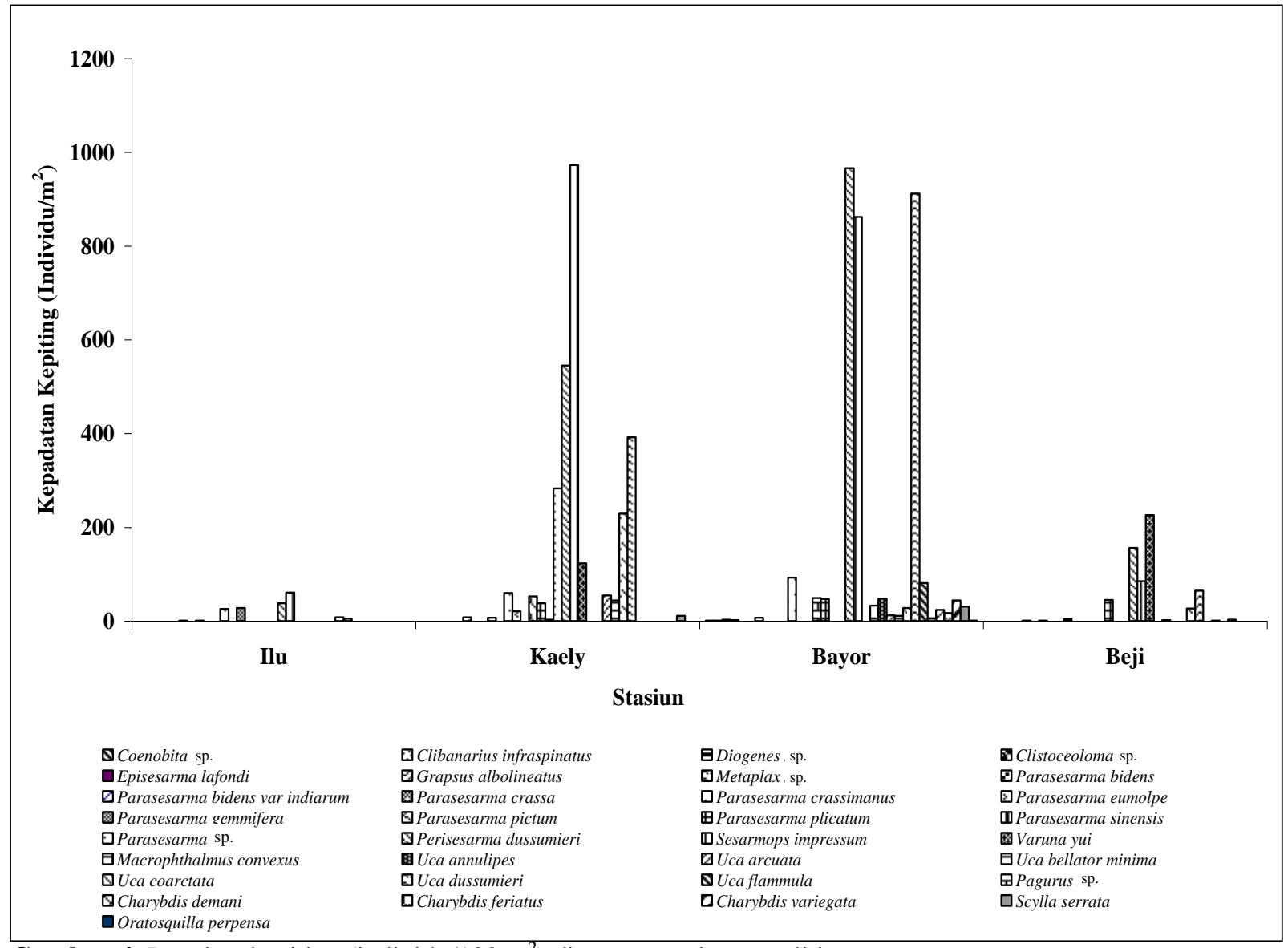

Gambar 4. Densitas kepiting (individu/100 $\mathrm{m}^{2}$ ) di empat stasiun penelitian. 
Pola sebaran yang mengelompok adalah penyebaran organisme di suatu habitat yang hidup secara berkelompok dalam jumlah tertentu. Suku Ocypodidae dan Grapsidae di stasiun penelitian selalu ditemukan dalam jumlah yang banyak dan mengelompok. Hal ini disebabkan kondisi lingkungan yang sesuai, adanya persediaan makanan yang tinggi dan jenis substrat yang cocok bagi jenis Krustasea. Kenyataan ini didukung oleh pernyataan Macintosh (1988), bahwa penyebaran kepiting fiddler tergantung pada ketersediaan makanan, kerapatan vegetasi, topografi dan kelembaban.
Penyebaran acak yang terjadi merupakan penyebaran acak yang cenderung mengelompok. Distribusi lokal menurut Mcnaughton \& Wolf (1990) dalam Werdiningsih (2005) menjelaskan bahwa penyebaran acak, menggambarkan keberadaan individu pada suatu tempat tidaklah mempengaruhi peluang adanya anggota populasi yang sama di suatu tempat yang berdekatan, dengan kata lain individu-individu menyebar dalam beberapa tempat dan mengelompok pada tempat lain.

Tabel 2. Pola sebaran jenis kepiting

\begin{tabular}{|c|c|c|c|c|c|}
\hline No & Jenis kepiting & Id & $X^{2}$ hitung & $\mathrm{X}^{2}$ tabel & Keterangan \\
\hline 1 & Charybdis demani & 1.65 & 61.76 & 70.58 & acak* \\
\hline 2 & Charybdis feriatus & 1.75 & 41.82 & 70.58 & $\operatorname{acak}^{*}$ \\
\hline 3 & Charybdis variegata & 1.02 & 19.25 & 70.58 & acak$^{*}$ \\
\hline 4 & Clibanarius infraspinatus & 0.00 & 3.000 & 70.58 & acak tdk ditemukan \\
\hline 5 & Clistoceoloma sp. & 1.00 & 42.00 & 70.58 & $\operatorname{acak}^{*}$ \\
\hline 6 & Coenobita sp. & 0.00 & 0.000 & 70.58 & acak tdk ditemukan \\
\hline 7 & Diogenes sp. & 45.00 & 132.00 & 70.58 & mengelompok \\
\hline 8 & Episesarma lafondi & 0.00 & 0.000 & 70.58 & acak tdk ditemukan \\
\hline 9 & Metopograpsus messor & 1.69 & 136.59 & 70.58 & mengelompok \\
\hline 10 & Macrophthalmus convexus & 2.60 & 275.55 & 70.58 & mengelompok \\
\hline 11 & Metaplax sp nov & 4.82 & 70.75 & 70.58 & mengelompok \\
\hline 12 & Neosesarma gemmiferum & 1.65 & 49.80 & 70.58 & acak \\
\hline 13 & Oratosquilla perpensa & 0.00 & 26.00 & 70.58 & acak \\
\hline 14 & Pagurus sp. & 0.46 & 48.32 & 70.58 & acak \\
\hline 15 & Parasesarma bidens & 0.00 & 5.000 & 70.58 & acak tdk ditemukan \\
\hline 16 & Parasesarma pictum & 15.59 & 1632.74 & 70.58 & mengelompok \\
\hline 17 & Parasesarma plicatum & 1.90 & 129.23 & 70.58 & mengelompok \\
\hline 18 & Parasesarma sp. & 1.272 & 621.77 & 70.58 & mengelompok \\
\hline 19 & Perisesarma bidens var indiarum & 7.00 & 35.00 & 70.58 & acak* $^{*}$ \\
\hline 20 & Perisesarma dussumieri & 15.47 & 2839.34 & 70.58 & mengelompok \\
\hline 21 & Perisesarma eumolpe & 5.79 & 59.69 & 70.58 & $\operatorname{acak}^{*}$ \\
\hline 22 & Pseudosesarma crassimanus & 1.04 & 306.34 & 70.58 & mengelompok \\
\hline 23 & Sarmatium germaini & 27.00 & 78.00 & 70.58 & mengelompok \\
\hline 24 & Sarmatium crassum & 18.00 & 112.00 & 70.58 & mengelompok \\
\hline 25 & Sarmatium sp. & 17.51 & 2544.18 & 70.58 & mengelompok \\
\hline 26 & Scylla serrata & 4.23 & 58.57 & 70.58 & $\operatorname{acak}^{*}$ \\
\hline 27 & Uca annulipes & 1.10 & 232.94 & 70.58 & mengelompok \\
\hline 28 & Uca arcuata & 1.16 & 85.27 & 70.58 & mengelompok \\
\hline 29 & Uca bellator minima & 1.48 & 568.62 & 70.58 & mengelompok \\
\hline 30 & Uca coarctata & 2.07 & 70.75 & 70.58 & mengelompok \\
\hline 31 & Uca dussumieri & 8.17 & 928.45 & 70.58 & mengelompok \\
\hline 32 & Uca flammula & 2.10 & 232.94 & 70.58 & mengelompok \\
\hline 33 & Varuna yui & 2.58 & 874.67 & 70.58 & mengelompok \\
\hline
\end{tabular}


Penyebaran secara acak dilakukan oleh organisme Charybdis demani, Charybdis feriatus, Charybdis variegata, Clistoceoloma sp., Perisesarma bidens var indiarum, Perisesarma eumolpe, dan Scylla serrata meskipun mereka memiliki nilai indeks Morisita sebesar 0,0 tetapi nilai $\mathrm{X}$ hitung yang diperoleh lebih kecil dari nilai $X_{\text {tabel, }}$, sehingga jenis ini memiliki pola penyebaran acak yang cenderung mengelompok. Selain itu ada jenis selama pengamatan hanya ditemukan satu ekor, seperti Clibanarius infraspinatus, Coenobita sp., Episesarma lafondi dan Parasesarma bidens. Jenis-jenis tersebut memiliki pola sebaran acak tidak ditemukan, artinya pada saat pengambilan contoh di lapangan sangat sulit ditemukan. Hal ini dimungkinkan faktor lingkungan tambak dan muara sungai sangat mempengaruhi penyebaran jenis-jenis tersebut disamping faktor substrat yang umumnya lumpur liat.

Untuk kepiting Uca spp. kebanyakan ditemukan di daerah terbuka. Menurut Sabar $e t$ al., (1978) dalam Agustianingsih, (2006) kepiting Uca spp. menyukai tempat-tempat yang relatif terbuka dengan dasar pasir campur lumpur. Kepiting tersebut aktif pada siang hari, mencari makan, menggali lubang dan mencari pasangan (Shields, 2003 dalam Agustianingsih, 2006). Kepiting suku Portunidae dan Squillidae ditemukan dalam pola sebaran yang acak (random), disebabkan tidak semua stasiun pengamatan cocok bagi jenis tersebut.

\section{Kesimpulan}

Berdasarkan hasil pengamatan Krustasea yang didapat di Delta Mahakam (Muara Ilu, Bayor, Kaely dan Beji) dapat disimpulkan bahwa kepiting yang ditemukan terdiri 7 suku, 59 jenis dan 6980 individu. Densitas kepiting bervariasi sesuai dengan karakteristik lingkungan di stasiun pengamatan. Densitas tertingi terdapat di Muara Bayor yaitu sebanyak 3279 ind/m2 diikuti Muara Kaely sebanyak 2845. ind $/ \mathrm{m} 2$, kemudian Muara Beji sebanyak 616 ind/m2 dan Muara Ilu sebanyak $168 \mathrm{ind} / \mathrm{m} 2$. Kondisi lingkungan di Muara Bayor dan muara Kaely lebih baik dibandingkan dengan kondisi di muara Beji dan muara Ilu. Pola penyebaran dari jenis kepiting cenderung mengelompok terutama untuk kepiting dari Suku Sesarmidae dan Ocypodidae sedangkan untuk kepiting Suku Portunidae, Diogenidae, Coenobitidae, Stomatopoda dan beberapa jenis kepiting dari suku Sesarmidae ditemukan pola sebarannya acak dan acak tidak ditemukan.

\section{Ucapan Terima Kasih}

Terima kasih disampaikan kepada Bapak Pramuji yang telah memberikan kesempatan untuk ikut dalam penelitian CoML, demikian juga kepada Bapak Sukardi yang telah membantu di lapangan dengan penuh tanggung jawab, sehingga penelitian ini dapat berjalan dengan baik.

\section{Daftar Pustaka}

Agustianingsih, F.D. 2006. Struktur Komunitas Kepiting di Ekosistem Mangrove Kawasan Hutan Lindung Angke Kapuk, DKI. Jakarta. Skripsi Sarjana Ilmu Kelautan, Departemen Manajemen Sumberdaya Perairan. Fakultas Perikanan dan Ilmu Kelautan, Institut Pertanian Bogor.

Banner, A.H. and Banner, D.M. 1966. The Alpheid Shrimp of Thailand, Siam. Soc. Mono. 3 (6): $168 \mathrm{pp}$.

Banner, D.M. and Banner, A.H. 1982. The Alpheid Shrimp of Australia. Part III. The Remaining Alpheids, Principally the Genus Alpheus and Family Ogyrididae. Rec. Australian Mus. 34 (1-2): 1-362.

Bliss, D.A. 1983. The Biology of Crustacea. Vol. 7. Behavior and Ecology. Academic Press. USA.

Brower, J.E. and Zar, J.H. 1977. Field and Laboratory Methods for General Ecology. W.M.J. Brown Company Publisher. Dubuque Iowa.

Crane, J. 1975. Fiddler Crabs of the World. Ocypodidae: Genus Uca. Priceton University Press.

Fize, A. and Serene, R. 1955. Les Pagurus du Vietnam. Hai Hoc Vien Institut Oceanographique, Nhatrang.

Frith, D.W., Tantanasiriwong, R. and Bathia, O. 1976. Zonation of Macrofauna on a Mangrove Shore. Phuket Island. Research Bulletin no. 10. Phuket Marine Biological Center. Thailand. 
Holthuis, L.B. 1955. The Recent Genera of the Caridean and Stanopodidae Shrimps (Class Crustacea, Order Decapoda, Supersection Natantia) with Keys for Their Determination. E.J. Brill. Leiden.

Hogarth, P.J. 1999. The Biology of Mangrove. Oxford University Press. Inc. New York.

Macintosh, D.J. 1988. The Physiology of Decapods of Mangrove Swamps. Zoological Symposium no. 59. The Zoological Society of London.

Macinthos, D.J., Aston, E.C. and Havanon, S. 2002. Mangrove Rehabilitation and Intertidal Biodiversity: A Study in Ranong Mangrove Ecosystem, Thailand. Elsevier Scientific Publication.

Moosa, M.K. dan Juwana, S. 1996. Kepiting Suku Portunidae dari Perairan Indonesia (Decapoda, Brachyura). Pusat Penelitian dan Pengembangan Oseanologi, Lembaga Ilmu Pengetahuan Indonesia, Jakarta.

Nybakken, J.W. 1992. Biologi Laut Suatu Pendekatan Ekologi. PT. Gramedia, Jakarta.

Odum, E.P. 1971. Fundamental of Ecology. Sounders College Publishing, USA.

Pramudji. 2004. Penelitian Biota pada Ekosistem Mangrove dan Estuaria di Pesisir Delta Mahakam, Kalimantan Timur. Laporan Akhir Program Kompetitif Pengembangan IPTEK. Pusat Penelitian Oseanografi-Lembaga Ilmu Pengetahuan Indonesia, Jakarta.
Pratiwi, A. 2002. Studi Struktur Komunitas dan Beberapa Aspek Biologis Makrobentos Krustasea di Komunitas Mangrove Pulau Ajkwa dan Pulau Kamora, Kabupaten Mimika, Papua. Skripsi Sarjana Ilmu Kelautan, Fakultas Perikanan dan Ilmu Kelautan Universitas Diponegoro, Semarang.

Purnobasuki, H. 2004. Potensi Mangrove sebagai Tanaman Obat. Biota IX (2): 125-126.

Rahawarin, Y.Y. 2005. Komposisi Vegetasi Mangrove di Muara Sungai Siganoi Sorong Selatan Papua. Biota X (3): 134-140.

Sakai, T. 1976 a. Crabs of Japan and Adjacent Seas. Kodansha Ltd.

Sakai, T. 1976 b. Crabs of Japan and Adjacent Seas. Plates. Kodansha Ltd.

Sasekumar, A. 1974. Distribution of Macrofauna on a Malayan Mangrove Shore. The Journal of Animal Ecology 43: 5-69.

Werdiningsih, R. 2005. Struktur Komunitas Kepiting di Habitat Mangrove Pantai Tanjung Pasir, Tanggerang, Banten. Skripsi. Fakultas Perikanan dan Ilmu Kelautan, Institut Pertanian Bogor. 